\title{
Artigo Original / Original Paper \\ Plantas trepadeiras em afloramentos rochosos no nordeste do Brasil: padrões de riqueza, similaridade florística e síndromes de dispersão
}

\author{
Climbing plants in rocky outcrops in Northeast Brazil: \\ patterns of richness, floristic similarity and dispersion syndromes
}

\author{
Danielly da Silva Lucena ${ }^{1,3,8}$, Bruno Cruz Souza ${ }^{2,4}$, Ellen Cristina Dantas Carvalho ${ }^{2,5}$, \\ Francisca Soares Araújo ${ }^{2,6}$ \& Marccus Alves ${ }^{1,7}$
}

\begin{abstract}
Resumo
Afloramentos rochosos são relevos residuais montanhosos que ocorrem em regiões tropicais, subtropicais e temperadas de todo o mundo. Nesse trabalho, nossos objetivos foram entender os padrões de riqueza e similaridade florística de plantas trepadeiras em afloramentos rochosos no nordeste do Brasil, bem como, compreender aspectos morfológicos e formas de dispersão dessas espécies. As análises foram realizadas utilizando uma lista florística de plantas trepadeiras registradas em inventários de afloramentos rochosos, nos estados da Paraíba e Pernambuco. Foram identificadas 143 espécies, 66 gêneros e 25 famílias. Quanto ao aspecto morfológico, $72 \%$ das espécies são trepadeiras herbáceas e $28 \%$ são lenhosas (lianas). O mecanismo de ascensão mais frequente foi o volúvel (66\%) e a síndrome de dispersão mais representativa foi autocoria (44\%). A riqueza de trepadeiras herbáceas e lenhosas foi positivamente correlacionada com a altitude e negativamente correlacionada com a distância do litoral e a temperatura; correlação negativa também foi observada entre a riqueza de trepadeiras herbáceas e a precipitação, enquanto para as lenhosas a riqueza se manteve constante nessa variável. A análise de similaridade florística resultou na formação de três grupos, sugerindo uma composição florística característica da matriz circundante, influenciada por fatores abióticos e tipos vegetacionais onde os afloramentos rochosos estão inseridos.
\end{abstract}

Palavras-chave: dispersão, fatores abióticos, flora, inselbergues, mecanismos de ascensão.

\begin{abstract}
Rocky outcrops are residual reliefs mountainous that occur in tropical, subtropical and temperate regions from all over the world. In this work, our objectives were to understand the richness patterns and floristic similarity of climbing plants, in rocky outcrops in Northeast Brazil, as well as to understand morphological aspects and dispersion forms of these species. The analyzes were carried out using a floristic list of climbing plants recorded in inventories of rocky outcrops, in the states of Paraíba and Pernambuco. We identified 143 species, 66 genera and 25 families. As for the morphological aspect, $72 \%$ of the species are herbaceous climbers and $28 \%$ are woody climbers (lianas). The most frequent ascending mechanism was the voluble $(66 \%)$, and the most representative dispersion syndrome was autochory (44\%). The richness of herbaceous and woody climbers was positively correlated with altitude, and negatively correlated with distance from the coast and temperature; negative correlation was also observed between richness of herbaceous climbers and precipitation, while for the woody the richness remained constant for this variable. The analysis of floristic similarity resulted in the formation of three groups, suggesting a floristic composition characteristic of the surrounding matrix, influenced by abiotic factors and vegetation types where rock outcrops are inserted.
\end{abstract}

Key words: dispersion, abiotic factors, flora, inselbergues, mechanisms of ascension.

Veja material suplementar em <https://doi.org/10.6084/m9.figshare.13105967.v1>

\footnotetext{
${ }^{1}$ Universidade Federal de Pernambuco - UFPE, Centro de Biociências, Recife, PE, Brasil.

${ }^{2}$ Universidade Federal do Ceará - UFC, Centro de Ciências, Depto. Biologia, Fortaleza, CE, Brasil.

${ }^{3}$ ORCID: <https://orcid.org/0000-0001-7028-174X>.

${ }^{4}$ ORCID: $<$ https://orcid.org/0000-0002-4746-2638>.

${ }^{5}$ ORCID: <https://orcid.org/0000-0002-6887-3970>.

${ }^{6}$ ORCID: <https://orcid.org/0000-0003-4661-6137>.

7 ORCID: < https://orcid.org/0000-0001-9281-2257>.

${ }^{8}$ Autor para correspondência: botanicadane@gmail.com
} 


\section{Introdução}

Inselbergues ou afloramentos rochosos são ilhas montanhosas ou relevos residuais que ocorrem em regiões tropicais, subtropicais e temperadas de todo mundo (Ab'Saber 2003). São comuns no continente americano e tratam-se de importantes unidades da paisagem frequentemente observadas por todo Brasil (França et al. 2006). Na Região Nordeste estão inseridos em diferentes tipos vegetacionais, desde as florestas úmidas até formações secas, também denominadas de Savana estépica (Veloso et al. 1991; Porembski 2000).

Apesar de submetidos a altos níveis de radiação solar e a pouca disponibilidade de substrato, água e nutrientes, os afloramentos rochosos comportam as mais variadas formas de vida e hábitos vegetais (Porembski 2007). Dentre esses, estão as plantas trepadeiras (herbáceas e lenhosas), que se desenvolvem principalmente em fissuras e fendas da rocha, habitats com solos mais profundos e maior retenção de umidade (Porembski 2007).

Plantas trepadeiras são definidas essencialmente como autotróficas, vasculares, que germinam no solo e mantêm contato com este durante todo o seu ciclo de vida, que perdem a habilidade de autossustentação à medida que crescem, necessitando, portanto, de uma sustentação mecânica (Acevedo-Rodrigues 2003).

Essas plantas formam um importante componente na estrutura das florestas, junto com árvores, arbustos, ervas terrestres, epífitas e parasitas (Gentry 1991), e contribuem com a diversidade vegetal e são fontes de alimento para diversos grupos de animais, vertebrados e invertebrados (Bongers et al. 2002; Gianoli 2004). Apresentam períodos de floração e frutificação complementar ao das árvores, e através da oferta de flores, frutos e folhas tornam estável a disponibilidade de recursos durante todo o ano (Morellato \& Leitão Filho 1996).

As plantas trepadeiras ocorrem em diversos ecossistemas, como as florestas temperadas (Gianoli et al. 2010) e regiões semiáridas ou desérticas (Rundel \& Franklin 1991), sendo mais abundantes em florestas tropicais, onde representam 25\% da riqueza (Gentry 1991; Acevedo-Rodrígues 2003). São frequentes em florestas jovens e áreas de borda, onde há maior disponibilidade de luz e suportes (forófitos) com menor diâmetro que facilitam a escalada (Gentry 1991; Dewalt et al. 2000; Fordjour et al. 2008).
Apresentam diversos mecanismos para fixação e ascensão nos suportes, como o caule volúvel, ramos escandentes, espinhos, gavinhas e raízes adventícias (Gentry 1991; AcevedoRodrigues 2003). Em áreas abertas como se caracterizam os afloramentos rochosos, as formas volúvel e gavinhosa têm sido registradas com maior frequência (Durigon \& Waechter 2011; Araújo 2014).

Padrões de riqueza e abundância de plantas trepadeiras são determinados por diversos fatores abióticos, como temperatura, precipitação, tipos de solos, disponibilidade de luz e altitude (Gentry \& Dodson 1987; Gentry 1991; Dewalt et al. 2000; Schnitzer 2005; Dewalt et al. 2015). Em escala local e considerando as angiospermas de forma geral, a distância geográfica entre áreas também é um importante fator na determinação da composição de espécies (Scudeller et al. 2001; Matos et al. 2013). Sendo especialmente importante em afloramentos rochosos, porque interfere nos limites de dispersão e na similaridade florística entre áreas (Gomes \& Alves 2009).

Os afloramentos rochosos apresentam características ambientais mais severas do que as registradas nas áreas de entorno, onde, apenas alguns grupos florísticos como Bromeliaceae, Orchidaceae e Poaceae são mais frequentes (Porembski 2007). Em consequência das condições ambientais a que estão submetidos, $80 \%$ da flora em afloramentos rochosos apresenta síndrome de dispersão abiótica (Barthlott et al. 1993; Porembski et al. 1998), o que facilita a troca de diásporos entre áreas próximas e aumenta a similaridade florística.

De modo geral, trepadeiras são menos abundantes em afloramentos rochosos $(\approx 10 \%$ de toda a vegetação) de florestas úmidas (Gröger 2000; Fonty et al. 2009) e secas (Sales-Rodrigues \& Brasileiro 2014) em relação a outros grupos de plantas. Possivelmente por isso, pouco se conhece sobre o estabelecimento e os padrões de riqueza e distribuição de plantas com exigências tão particulares como as trepadeiras, nesses ecossistemas.

Diante do exposto, nossos objetivos foram: entender os padrões de riqueza e similaridade florística de plantas trepadeiras em afloramentos rochosos do nordeste do Brasil, bem como, compreender os aspectos morfológicos, mecanismos de ascensão e formas de dispersão dessas espécies. Buscando responder: (1) Qual a influência de fatores abióticos (altitude, temperatura, precipitação e distância da costa) sobre a riqueza de 
trepadeiras herbáceas e lenhosas nos afloramentos rochosos do nordeste? (2) Por se tratar de áreas com características físicas e ambientais semelhantes, os afloramentos rochosos apresentam um único conjunto florístico de plantas trepadeiras?

\section{Material e Métodos}

\section{Área de estudo}

As 15 áreas de afloramentos rochosos selecionadas nesse trabalho (Tab. 1) distribuem-se nos estados da Paraíba e Pernambuco, nordeste do Brasil. Essas áreas sofrem influência do planalto da Borborema, que é uma importante unidade geomorfológica do nordeste oriental (Fig. 1), dessa forma, apresentam diferentes tipos de vegetação em seu entorno (Savana Estépica - SET, Floresta Estacional Decidual - FED e Floresta Estacional Semidecidual - FES) (Veloso et al. 1991), que são classificadas em estágios iniciais e intermediários de sucessão ecológica.

Os afloramentos rochosos localizados a leste desse planalto (áreas 9, 11 a 15) são circundados por formações florestais úmidas (FES), em função do relevo, que faz com que as massas de ar se depositem e precipitem nas vertentes a barlavento. Enquanto as áreas a oeste ( 1 a 4) afastadas da costa atlântica estão

Tabela 1 - Áreas de afloramentos rochosos estudadas $(\mathrm{BVT}=$ Boa Vista; EPB = Pedra do Espinho Branco; ESP = Esperança; LUR = Lajedo do Urucu; PAB = Pedra Antônio Bezerra; PCH = Pedra do Cachorro; PCR1 = Pedra do Cruzeiro 1; PCR2 = Pedra do Cruzeiro 2; PCV = Pedra Cabeça de Velho; PEA = Pedra de Pedro Augustinho; $P E F=$ Pedra Furada; PEG = Pedra do Guariba; PIA = Pedra da Pia; PUX = Puxinanã; TRA = Trapiá), com número correspondente, tipos de vegetação do entorno - Veg (SET = Savana Estépica; FED = Floresta Estacional Decidual; FES = Floresta Estacional Semidecidual), localização, altitude (Alt), precipitação (Prec), temperatura média (Temp), distancia da costa (Dist), riqueza de plantas trepadeiras - Riq $(\mathrm{G}=$ geral; $\mathrm{H}$ = herbáceas; $\mathrm{L}=$ lianas) e referências, N/P (dados não publicados).

Table 1 - Areas of rock outcrops studied $(\mathrm{BVT}=\mathrm{Boa}$ Vista; $\mathrm{EPB}=$ Pedra do Espinho Branco; ESP = Esperança; LUR = Lajedo do Urucu; $\mathrm{PAB}=$ Pedra Antônio Bezerra; PCH = Pedra do Cachorro; PCR1 = Pedra do Cruzeiro 1; PCR2 = Pedra do Cruzeiro 2; PCV = Pedra Cabeça de Velho; PEA = Pedra de Pedro Augustinho; PEF = Pedra Furada; PEG = Pedra do Guariba; PIA = Pedra da Pia; PUX = Puxinanã; TRA = Trapiá), with corresponding number, vegetation types of the surroundings - Veg (SET = Steppe Savanna; FED = Deciduous Seasonal Forest; FES = Semideciduous Seasonal Forest), localization, altitude (Alt), precipitation (Prec), mean temperature (Temp), distance of the coast (Dist), richness of climbing plants - Riq $(\mathrm{G}=$ general; $\mathrm{H}=$ herbaceous; $\mathrm{L}=$ woody) and references, $\mathrm{N} / \mathrm{P}$ (unpublished data).

\begin{tabular}{|c|c|c|c|c|c|c|c|c|c|c|c|}
\hline \multirow[t]{2}{*}{ Área } & \multirow[t]{2}{*}{$\mathbf{N}^{\mathbf{o}}$} & \multirow[t]{2}{*}{ Veg } & \multirow[t]{2}{*}{ Localização } & \multirow{2}{*}{$\begin{array}{l}\text { Alt } \\
\text { (m) }\end{array}$} & \multirow{2}{*}{$\begin{array}{l}\text { Prec } \\
(\mathbf{m m})\end{array}$} & \multirow{2}{*}{$\begin{array}{l}\text { Temp } \\
\left({ }^{\circ} \mathrm{C}\right)\end{array}$} & \multirow{2}{*}{$\begin{array}{l}\text { Dist. } \\
\text { (km) }\end{array}$} & \multicolumn{3}{|c|}{ Riq } & \multirow[t]{2}{*}{ Referência } \\
\hline & & & & & & & & G & H & $\mathbf{L}$ & \\
\hline EPB & 1 & SET & Patos, PB & 330 & 600 & 25,5 & 269 & 13 & 12 & 01 & Lucena et al. (2015) \\
\hline PEA & 2 & SET & Patos, PB & 390 & 609 & 25,2 & 261 & 17 & 14 & 03 & $\mathrm{~N} / \mathrm{P}$ \\
\hline TRA & 3 & SET & Patos, PB & 349 & 600 & 25,6 & 270 & 12 & 11 & 01 & $\mathrm{~N} / \mathrm{P}$ \\
\hline PIA & 4 & SET & Patos, PB & 420 & 600 & 25,4 & 261 & 14 & 13 & 01 & $\mathrm{~N} / \mathrm{P}$ \\
\hline PUX & 5 & FED & Puxinanã, PB & 700 & 678 & 21,6 & 121 & 21 & 18 & 03 & Tölke et al. (2011) \\
\hline PEF & 6 & FED & Venturosa, PE & 689 & 620 & 22,2 & 240 & 25 & 20 & 05 & Gomes et al. (2011) \\
\hline ESP & 7 & FED & Esperança, PB & 631 & 680 & 21,7 & 111 & 18 & 08 & 10 & Porto et al. (2008) \\
\hline BVT & 8 & FED & Boa Vista, PB & 478 & 870 & 22,6 & 147 & 10 & 07 & 03 & Machado Filho (2011) \\
\hline PAB & 9 & FES & Bezerros, PE & 835 & 749 & 21,2 & 115 & 19 & 13 & 06 & Gomes \& Alves (2009) \\
\hline $\mathrm{PCH}$ & 10 & FED & São Caetano, PE & 760 & 560 & 22,1 & 144 & 38 & 30 & 08 & Macedo (2012) \\
\hline PCR2 & 11 & FES & Bezerros, PE & 839 & 631 & 22,7 & 100 & 36 & 26 & 10 & Lucena et al. (2017) \\
\hline LUR & 12 & FES & Maraial, PE & 451 & 1300 & 22,4 & 80 & 13 & 08 & 05 & Gomes \& Leite (2013) \\
\hline PEG & 13 & FES & Agrestina, PE & 620 & 740 & 21,2 & 100 & 34 & 28 & 06 & Gomes \& Alves (2010) \\
\hline PCV & 14 & FES & Agrestina, PE & 740 & 600 & 20,8 & 120 & 12 & 09 & 03 & Gomes \& Alves (2010) \\
\hline PCR1 & 15 & FES & Jaqueira, PE & 730 & 1300 & 21,0 & 95 & 20 & 14 & 06 & Melo et al. (2016) \\
\hline
\end{tabular}


inseridas em formações florestais secas (SET). Sob o planalto $(5$ a 8,10$)$ ocorrem formações florestais de transição (FED) entre os ambientes úmidos e secos (Rodal et al. 2005) (Tab. 1).

De acordo com dados do INMET (2017), nas áreas inseridas em FED e FES a precipitação total anual dos últimos 20 anos variou de 600 a 2.600 milímetros e a temperatura média anual apresentou variação de 22 a $25^{\circ} \mathrm{C}$. Já nas áreas de SET, para o mesmo período a precipitação ficou entre $400 \mathrm{e}$ 1.200 milímetros e a temperatura entre 25 e $26^{\circ} \mathrm{C}$. A distância dos afloramentos em relação à zona costeira do atlântico é de 80 a $270 \mathrm{~km}$ (Tab. 1).

\section{Composição, padrões de riqueza}

\section{e similaridade florística}

Para determinar a composição florística e os padrões de riqueza das plantas trepadeiras nas áreas estudadas, todas as espécies com hábito trepador registradas em inventários florísticos foram selecionadas no presente estudo (Tab. 1). A listagem florística gerada foi revisada para averiguação de sinonímias e atualizações nomenclaturais (BFG 2018). Cada voucher citado nos inventários foi devidamente analisado nos herbários para confirmação das identificações. Complementar aos inventários disponíveis, coletas adicionais de plantas trepadeiras foram realizadas em cada uma das áreas selecionadas, seguindo metodologia usual em taxonomia (Mori et al. 1985).
Para comparar a riqueza com as variáveis ambientais, valores de temperatura e precipitação média foram extraídos do banco de dados WorldClim - período 1970-1990 (Fick \& Hijmans 2017) com o software DIVA-GIS 7.5 (Hijmans et al. 2001), utilizando a coordenada geográfica de cada área. A distância dos afloramentos até a zona costeira do atlântico foi determinada em quilômetros, com auxílio do Google Earth (2019). A altitude de cada uma das áreas estudadas foi obtida com auxílio do Sistema de Posicionamento Global (GPS).

A influência das variáveis ambientais (altitude, distância da costa, temperatura e precipitação) sobre a riqueza de trepadeiras herbáceas e lenhosas foi relacionada através de regressões lineares simples (Zar 1996), utilizando a linguagem de programação estatística R (R Core Team 2018).

Para a análise de similaridade florística, uma matriz binária com dados de presença e ausência das espécies em cada área foi elaborada. O índice de Jaccard $(\mathrm{Sj})$, que expressa a similaridade entre ambientes baseando-se no número de espécies comuns foi utilizado. Com base neste índice um dendrograma de similaridade florística foi gerado, utilizando análise de agrupamento no algoritmo UPGMA, no software Past 2.1 (Hammer et al. 2001). Nesse mesmo software, um teste de Mantel foi utilizado para avaliar a influência da distância

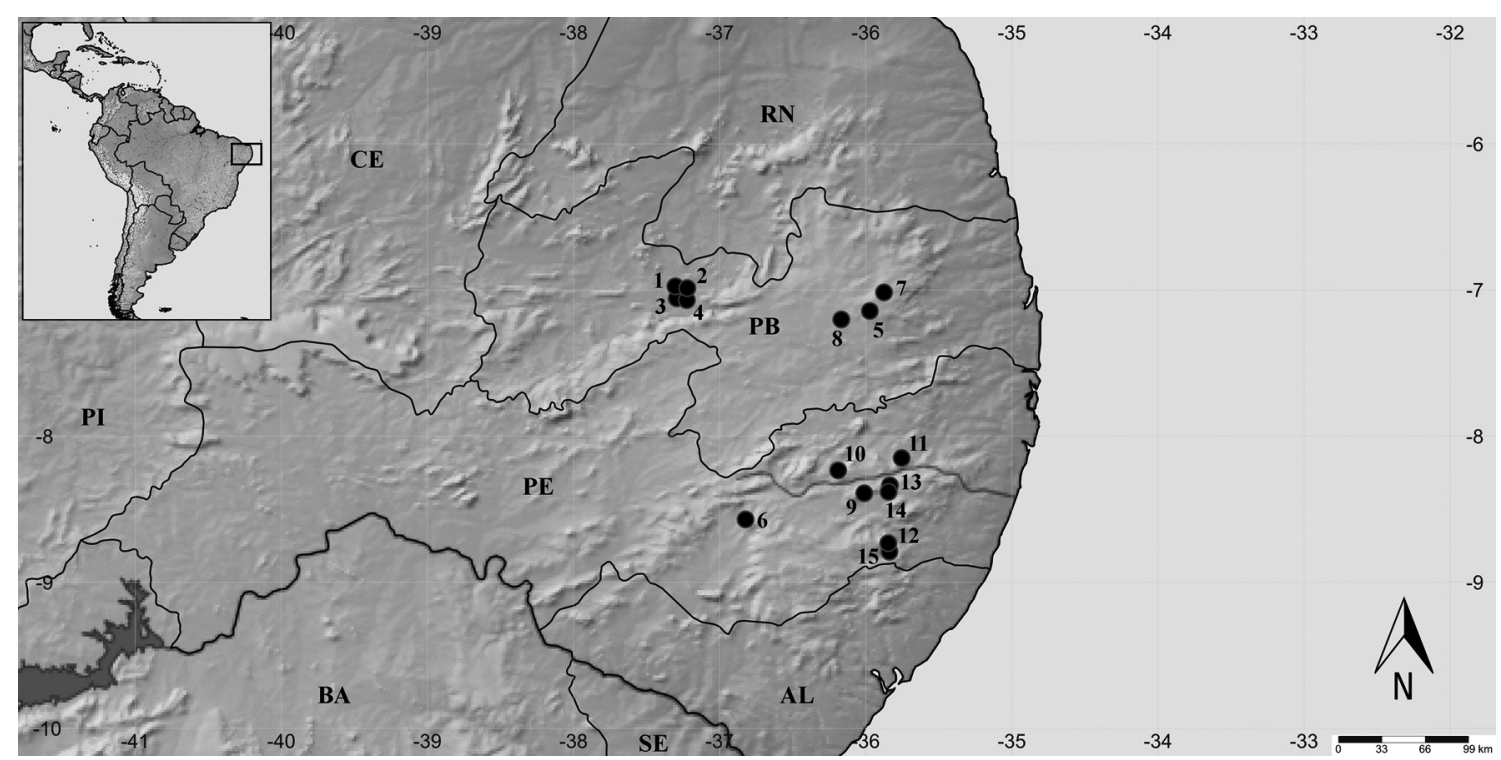

Figura 1 - Mapa com a localização dos afloramentos rochosos incluídos nesse trabalho.

Figure 1 - Map with the location of rock outcrops included in this work. 
geográfica entre as áreas e os agrupamentos florísticos formados.

Os levantamentos florísticos selecionados nesse estudo (Tab. 1) foram realizados essencialmente sobre os afloramentos rochosos. Informações sobre a distribuição das espécies nessas áreas foram confirmadas durante as expedições de campo, bem como, durante a análise das coleções depositadas nos herbários, onde, espécies com localização duvidosa ou coletadas no entorno dos afloramentos foram excluídas desse estudo.

Aspectos morfológicos do caule, mecanismos de ascensão e síndromes de dispersão

Em relação aos aspectos morfológicos, as trepadeiras foram classificadas em herbáceas quando apresentaram caule delgado, suculento e com epiderme em geral verde, e em lianas quando apresentaram crescimento secundário, sendo marcadamente lenhosas (Gentry 1991; AcevedoRodrigues 2003). Os mecanismos de ascensão ou adaptação para a escalada (volúveis, gavinhosas, espinhosas, escandentes e com raízes adventícias) foram definidos de acordo com a classificação proposta por Acevedo-Rodrigues (2003).

As espécies foram classificadas quanto às síndromes de dispersão, através da análise dos frutos jovens e/ou maduros provenientes das coletas e dos espécimes analisados nos herbários. Espécimes sem frutos foram classificadas com base na literatura disponível. Foram adotadas três categorias: Anemocóricas - quando os diásporos apresentam-se alados, plumosos ou inflados; zoocóricas - com atrativos e/ou fontes alimentares em seus diásporos, assim como as que possuem cerdas, espinhos, ganchos, estruturas adesivas ou qualquer adaptação que facilite aderência a superfície do corpo de animais; autocóricas - quando não se encaixam nas duas categorias descritas anteriormente, sendo incluídas nessa categoria as espécies barocóricas, com dispersão explosiva e aquelas que são carreadas pela movimentação do sedimento (Pijl 1982).

\section{Resultados}

Foram identificadas 143 espécies, distribuídas em 66 gêneros e 25 famílias. Convolvulaceae (33 spp. - 23\%), Apocynaceae e Fabaceae (16 spp. cada - 11\%), Vitaceae (10 spp. - 7\%), Sapindaceae, Cucurbitaceae e Malpighiaceae ( 8 spp. cada - 5\%) foram as mais representativas, com aproximadamente $70 \%$ do total de espécies. Os gêneros com maior riqueza foram Ipomoea (17 ssp.), Cissus e Jacquemontia (9 ssp. cada), Dioscorea (7 ssp.), Ditassa e Passiflora (6 ssp. cada) (Tab. S1, disponibilizada no material suplementar $<$ https:// doi.org/10.6084/m9.figshare.13105967.v1>).

Quanto ao aspecto morfológico do caule, $72 \%$ (104 ssp.) das espécies são herbáceas e 28\% (39 ssp.) são lianas. As famílias Alstroemeriaceae, Aristolochiaceae, Commelinaceae, Cucurbitaceae, Dioscoreaceae, Euphorbiaceae, Menispermaceae, Ranunculaceae e Vitaceae foram representadas exclusivamente por trepadeiras herbáceas. Enquanto as espécies em Asteraceae, Bignoniaceae, Boraginaceae, Celastraceae, Combretaceae, Marcgraviaceae e Polygalaceae são exclusivamente lianas. Para as demais famílias catalogadas nesse estudo, espécies herbáceas e lenhosas foram registradas (Tab. S1, disponibilizada no material suplementar <https://doi.org/10.6084/ m9.figshare.13105967.v1>).

A riqueza de trepadeiras entre as áreas estudadas variou de 10 a 38 espécies. Para as trepadeiras herbáceas esse número ficou entre $7 \mathrm{e}$ 30 , enquanto para as lianas entre 1 e 10 espécies. Os afloramentos com maior riqueza estão circundados por FED e FES, onde o número máximo de espécies por área foi 38 e 36, respectivamente, enquanto nas áreas de SET o número máximo de espécies registrado por área foi 17 (Tab. 1).

Em relação ao mecanismo de ascensão, 66\% das espécies foram volúveis, enquanto as formas gavinhosa e escandente foram representadas por $28 \%$ e $6 \%$ das espécies, respectivamente. Avaliando as trepadeiras herbáceas, a volubilidade $(80 \%)$ foi mais comum, seguida pelas formas gavinhosa $(14 \%)$ e escandente $(6 \%)$. Para as lianas a forma mais frequente também foi a volúvel $(47,5 \%)$, seguida pela gavinhosa $(37,5 \%)$ e escandente $(15 \%)$.

A autocoria $(44 \%)$ foi a síndrome de dispersão mais comum entre as espécies, sendo registradas também anemocoria (34\%) e zoocoria $(22 \%)$. Considerando somente as trepadeiras herbáceas, a autocoria (52\%) foi mais frequente, seguida pela anemocoria $(25 \%)$ e zoocoria $(23 \%)$. Enquanto para as lianas, a maior frequência foi de espécies anemocóricas $(60 \%)$, seguidas por autocóricas (24\%) e zoocóricas (16\%). As famílias Apocynaceae, Bignoniaceae e Dioscoriaceae foram exclusivamente anemocóricas, enquanto Convolvulaceae e Fabaceae foram predominantemente autocóricas. 
A similaridade florística entre os afloramentos rochosos foi baixa, e indicou a formação de três conjuntos ou agrupamentos florísticos definidos de acordo com o tipo de vegetação onde as áreas estão inseridas (Fig. 2). O agrupamento um (1) é composto por áreas localizadas na depressão sertaneja a oeste do Planalto da Borborema (TRA, PEA, EPB, PIA), circundadas por Savana Estépica (SET). O agrupamento dois (2) é formado pelas áreas localizadas sob a unidade geoambiental do Planalto da Borborema (PCH, ESP, BVT, PEF, PUX), onde predomina a Floresta Estacional Decidual (FED). O terceiro grupo (3) é composto pelos afloramentos situados em áreas de Floresta Estacional Semidecidual (FES), localizados na encosta leste do Planalto da Borborema (LUR, PCR1, PCR2, PEG, PCV, PAB). Correlação positiva e significativa foi observada entre a distância geográfica e a similaridade florística das áreas estudadas (Mantel $r=0,55 ; P=0,0002$ ).

A riqueza de espécies apresentou correlação positiva com a altitude para as trepadeiras herbáceas $\left(r^{2}=0,393 ; P=0,003\right)$ e lianas $\left(r^{2}=\right.$ 0,$385 ; P=0,006$ ) (Fig. 3a). Para as variáveis temperatura (herbáceas $r^{2}=0,067 ; P=0,268$; lianas $\left.r^{2}=0,347 ; P=0,010\right)$ e precipitação (herbáceas $r^{2}=0,159 ; P=0,081$; lianas $r^{2}=0,016$; $P=0,607)$, correlação negativa não significativa entre a riqueza de espécies herbáceas e essas duas variáveis foi observada, enquanto para as trepadeiras lenhosas (lianas), correlação negativa não significativa foi observada para temperatura, para a variável precipitação essa riqueza se manteve constante (Fig. 3b-c). Correlação negativa e significativa entre a riqueza de espécies e distância da costa foi detectada apenas para lianas $\left(r^{2}=0,359 ; P=0,009\right)$, enquanto para espécies herbáceas essa relação negativa não foi significativa $\left(r^{2}=0,028 ; P=0,479\right)$ (Fig. 3d).

\section{Discussão}

Embora apresentem características físicas e ambientais semelhantes (Ab'Saber 2003), os afloramentos rochosos estudados possuem diferentes conjuntos ou grupos florísticos de plantas trepadeiras. O que sugere uma composição florística característica da matriz circundante e influenciada pelos tipos vegetacionais onde essas áreas estão inseridas. Variações na altitude, temperatura, precipitação e distância da costa atlântica têm importante influência nos padrões de riqueza de plantas trepadeiras em afloramentos rochosos do nordeste do Brasil.

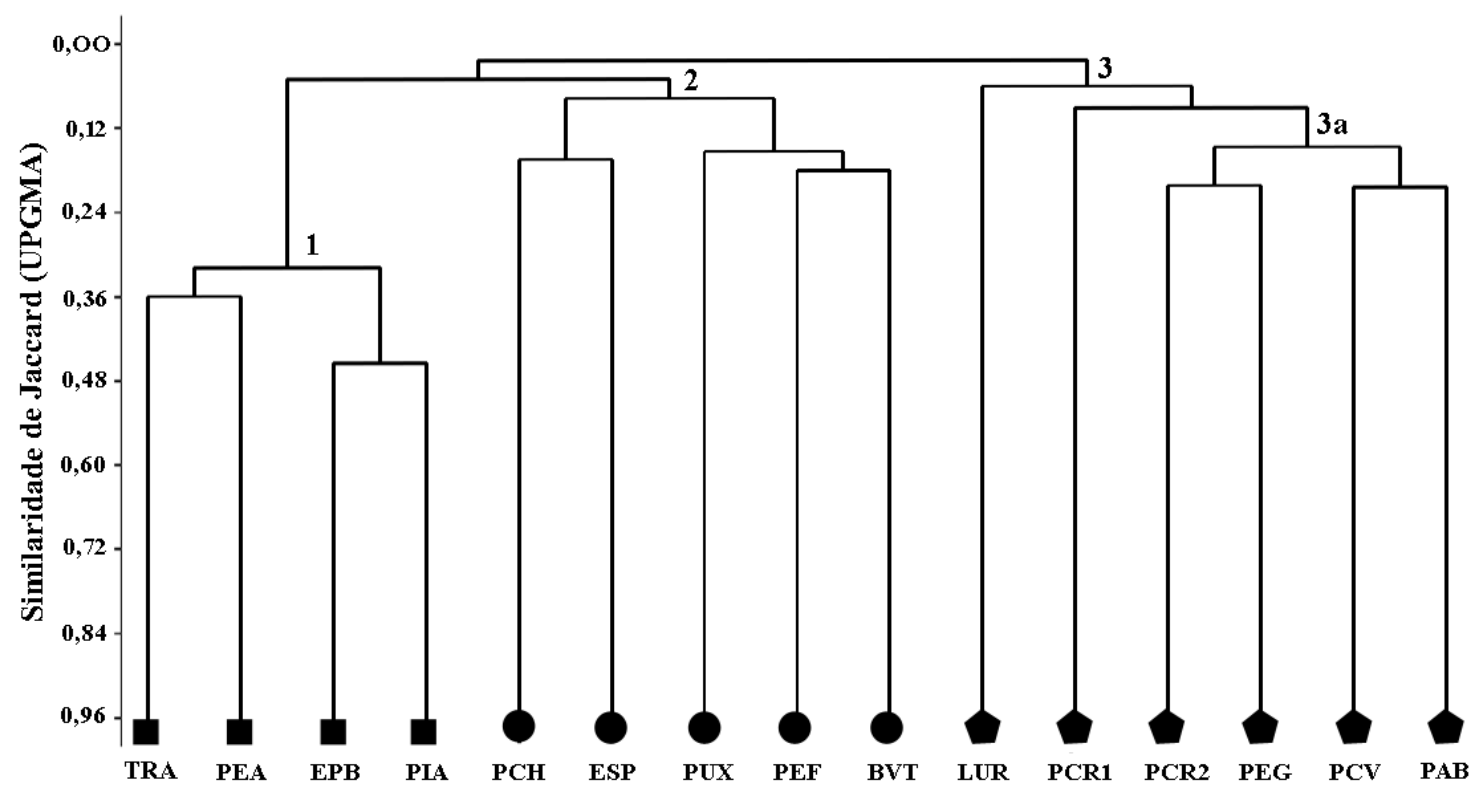

Figura 2 - Dendrograma de Similaridade florística entre as áreas de afloramentos rochosos, e os tipos vegetacionais onde os afloramentos estão inseridos (Quadrado = SET - Savana Estépica; Círculo = FED - Floresta Estacional Decidual; Pentágono = FES - Floresta Estacional Semidecidual).

Figure 2 - Dendrogram of floristic similarity between the areas of rocky outcrops, and the vegetation types where the outcrops are inserted $($ Square $=$ SET - Steppe Savanna; Circle $=$ FED - Seasonal Deciduous Forest; Pentagon $=$ FES - Seasonal Semideciduous Forest $)$. 
Para cada uma das áreas estudadas, o número de espécies registrada foi superior ao descrito para o hábito em outros afloramentos do nordeste, nos estados da Bahia (França et al. 2005, 2006; Conceição et al. 2007) e do Ceará (Araújo et al. 2008). A maior riqueza observada nesse estudo pode estar relacionada a coletas direcionadas exclusivamente para trepadeiras, nos afloramentos rochosos estudados. Ainda em relação a riqueza, cerca de 40 espécies aqui identificadas não foram citadas na lista de plantas trepadeiras para a Caatinga (Araújo 2014), sendo o presente trabalho, uma contribuição para atualização da riqueza de trepadeiras nesse domínio fitogeográfico e no nordeste brasileiro.

As famílias Apocynaceae, Convolvulaceae e Fabaceae se destacaram em outros levantamentos florísticos realizados na Região Nordeste do Brasil, em áreas de Savana Estépica e Floresta Estacional Semidecidual (Araújo \& Alves 2010; Oliveira et al. 2012; Araújo 2014; Brandão 2014; Delgado Jr. \& Alves 2017; Oliveira et al. 2015), sendo Malpighiaceae e Cucurbitaceae representativas em alguns desses levantamentos.
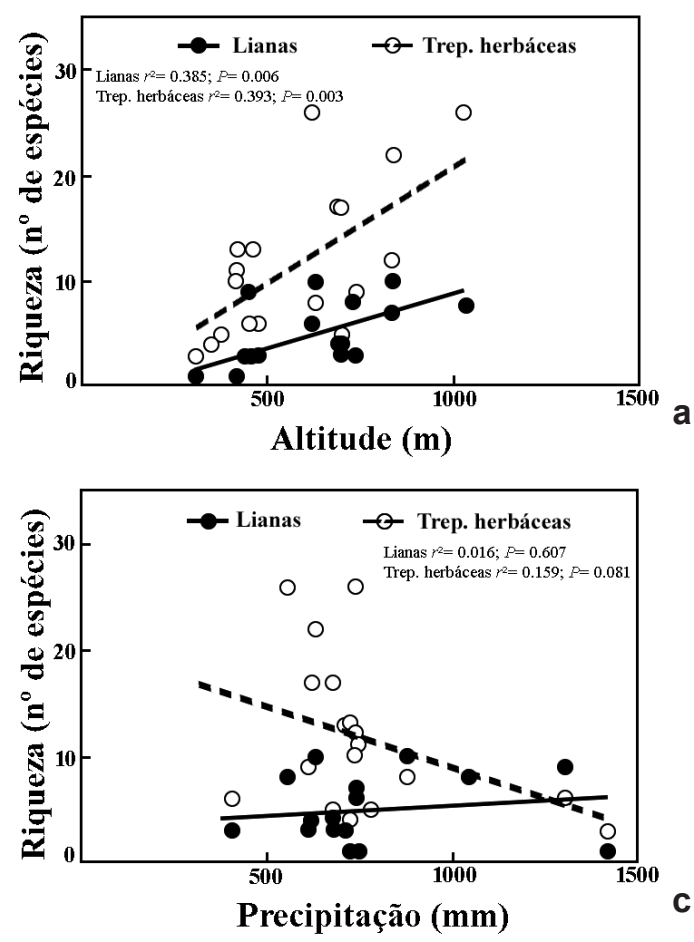

Para a Região Sudeste do país, inventários florísticos realizados em áreas de Floresta Estacional Semidecidual evidenciam Apocynaceae, Fabaceae e Malpighiaceae como famílias mais representativas, citando também Bignoniaceae e Sapindaceae com expressiva riqueza (Udulutsch et al. 2004, 2010; Barros et al. 2009; Vargas \& Araújo 2014; Vargas et al. 2018). Essas duas últimas famílias, apesar de registradas nesse trabalho, não apresentaram riqueza significativa quando comparada aos estudos citados acima. Bignoniaceae e Sapindaceae são compostas essencialmente por lianas e, de acordo com Gentry (1991), esse grupo ocorre preferencialmente no interior de florestas, sendo aceitável a menor riqueza de famílias com esse hábito nos afloramentos rochosos.

A família Vitaceae apresentou expressiva riqueza nesse trabalho, com número de espécies semelhante ao registrado por Araújo (2014) para o domínio fitogeográfico da Caatinga. As espécies nessa família são herbáceas, o que configura uma adaptação para sobrevivência em bordas de florestas ou ambientes xéricos como os afloramentos rochosos (Gentry 1991).
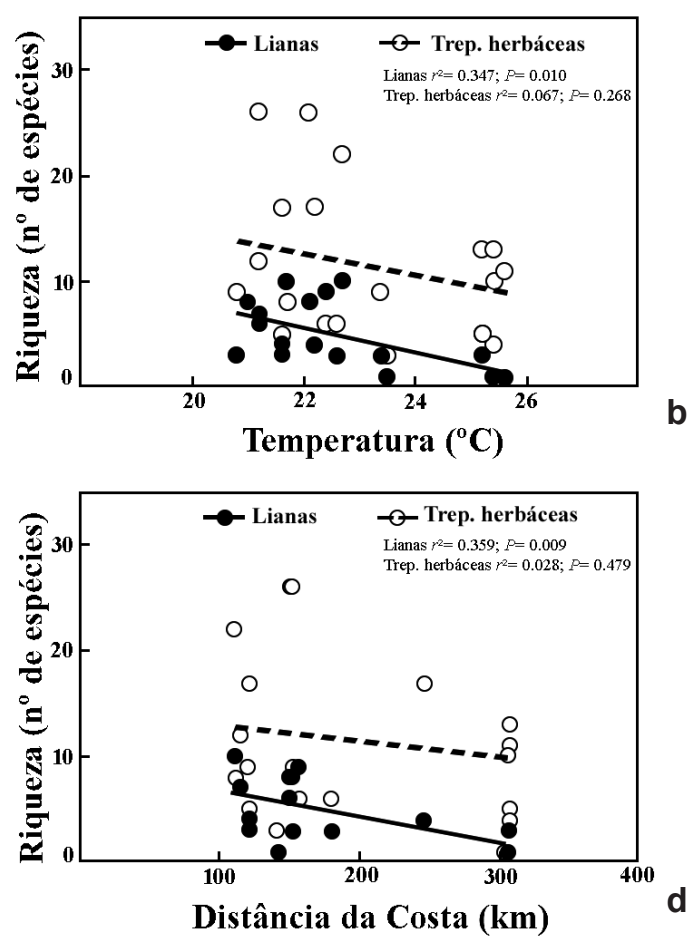

Figura 3 - a-d. Regressões lineares entre a riqueza de plantas trepadeiras (herbáceas e lenhosas) e as variáveis ambientais - a. altitude $(\mathrm{m})$; b. temperatura $\left({ }^{\circ} \mathrm{C}\right)$; c. precipitação $(\mathrm{mm})$; d. distância do litoral $(\mathrm{km})$.

Figure 3 - a-d. Linear regressions between the richness of climbing plants (herbaceous and woody) and the environmental variables $-\mathrm{a}$. altitude $(\mathrm{m})$; b. temperature $\left({ }^{\circ} \mathrm{C}\right)$; c. precipitation $(\mathrm{mm})$; d. distance from the coast $(\mathrm{km})$. 
Em síntese, as famílias com maior riqueza registradas nesse trabalho estão entre as mais representativas na região Neotropical (Gentry 1991). Esses dados evidenciaram que os afloramentos rochosos comportam além de uma flora exclusiva adaptada a esses ambientes, grupos florísticos relacionados a fragmentos florestais próximos.

No presente estudo, a maioria das espécies registradas são trepadeiras herbáceas. Esse hábito também foi mais representativo em florestas tropicais do nordeste brasileiro (Araújo \& Alves 2010; Oliveira et al. 2015) e em florestas subtropicais e temperadas da América do Sul (Durigon et al. 2014). Contudo, grande parte dos levantamentos que incluem trepadeiras de forma geral (herbáceas e lianas) têm apresentado maior riqueza das lenhosas em relação as herbáceas (Udulutsch et al. 2004; Barros et al. 2009; Vargas et al. 2013; Brandão 2014; Vargas \& Araújo 2014; Delgado Jr. \& Alves 2017; Vargas et al. 2018). O baixo número de lianas registrado nas áreas estudadas pode estar relacionado a pouca disponibilidade de substrato nesses ambientes, o que limita a retenção de água (Porembski 2007) e dificulta o estabelecimento de espécies com ciclos de vida perene, como as trepadeiras lenhosas.

Outro fator a ser considerado, é que as lianas são eficientes na condução hídrica devido a presença de vasos com grande calibre. Contudo, em ambientes com baixa disponibilidade de água, espécies com esse hábito se tornam mais vulneráveis a cavitação (formação de bolhas de ar no interior dos elementos de vaso) e, por conseguinte, ao embolismo nos vasos, sendo compreensível a baixa riqueza de trepadeiras lenhosas nos afloramentos rochosos estudados (Sperry et al. 2008; Durigon et al. 2014; Carvalho et al. 2016).

$\mathrm{O}$ mecanismo de ascensão mais frequente registrado nesse trabalho (volúvel) se destaca em outros estudos com trepadeiras no Brasil, sendo as formas gavinhosa e escandente também identificadas com frequência (Udulutsch et al. 2004; Appolinário 2008; Barros et al. 2009; Vargas et al. 2013; Araújo 2014; Villagra \& Romaniuc Neto 2014; Oliveira et al. 2015; Delgado Jr. \& Alves 2017; Vargas et al. 2018). Geralmente a forma volúvel está associada a ambientes em estágios intermediários de sucessão e com disponibilidade de luz, como clareiras e bordas de floresta (Villagra 2012; Araújo 2014), sendo justificável a alta representatividade dessas adaptações nas áreas estudadas.
Autocoria e anemocoria foram as síndromes de dispersão mais representativas nesse estudo e, frequentemente estão associadas a ambientes semiáridos, dossel e bordas de florestas (Silva \& Rodal 2009). Os afloramentos rochosos apresentam aridez microclimática e vegetação espaçada, fatores que favorecem a dispersão por vetores abióticos e justificam os resultados encontrados (Morellato \& Leitão filho 1996; Porembski et al. 1998; Araújo et al. 2008; Silva \& Rodal 2009). O baixo percentual de espécies zoocóricas registradas nesse trabalho evidencia a rara ocorrência de trepadeiras com frutos carnosos em afloramentos rochosos e áreas semiáridas (Araújo et al. 2008; Silva \& Rodal 2009), possivelmente, por esse tipo de fruto está associado a ambientes úmidos como os sub bosques de florestas, por exemplo (Silva \& Rodal 2009; Domingues et al. 2013).

$\mathrm{Na}$ análise de similaridade foram evidenciados três grupos. As áreas que compõem cada um desses grupos apresentam composição florística similar, provavelmente, em função das semelhanças nas condições abióticas e tipos vegetacionais onde os afloramentos estão inseridos, considerando que a vegetação circundante é uma das principais fontes de propágulos em afloramentos rochosos (Scarano 2007; Araújo et al. 2008).

As áreas que constituem o agrupamento 1 são relativamente próximas geograficamente, de acordo com Oliveira Filho \& Machado (1993) fragmentos com proximidade geográfica ou inseridos em unidades fisionômicas similares apresentam maior similaridade florística, o que justifica a formação desse agrupamento.

Áreas que constituem o agrupamento 2 estão sob faixas latitudinais próximas, com pouca variação na distância da costa e, possivelmente, sob influência das mesmas variações geomorfológicas e climáticas, o que explica a composição florística similar. Fatores como a distância do oceano e altitude influenciam o clima, estando fortemente ligados à similaridade florística e riqueza de espécies em uma região, assim como, as configurações do relevo e condições edáficas (Sampaio 2003; Rodal \& Sales 2007; Cerqueira et al. 2008).

No terceiro agrupamento é possível identificar um subgrupo com quatro áreas (3a) que estão sob influência de altitude e precipitação semelhantes, onde possivelmente há maior troca de diásporos, bem como, duas áreas (LUR e PCR1) com floras distintas $(J=0,0882)$, apesar de geograficamente próximas. A baixa similaridade entre essas duas últimas áreas pode estar relacionada às 
características da vegetação do entorno. LUR está circundado por florestas em diferentes estágios sucessionais, onde predominam plantações de cana-de-açúcar e pastagem (Gomes \& Leite 2013), enquanto PCR1, localiza-se em uma Unidade de Conservação e é circundado por Floresta Atlântica em estágios intermediários de sucessão (Melo et al. 2016).

Considerando as condições ambientais e o histórico de uso onde as duas áreas estão inseridas, é compreensível que mesmo geograficamente próximas e com características abióticas similares, ambas não compartilhem um número de espécies significativo. Apenas Mikania micrantha Kunth., Merremia macrocalyx (Ruiz \& Pav.) O’Donell e Cissus erosa Rich. são comuns às duas áreas.

O padrão de agrupamento florístico identificado nesse trabalho é semelhante ao encontrado por Rodal et al. (2008), que avaliaram o componente arbóreo e arbustivo para o nordeste oriental do Brasil e concluíram que o planalto da Borborema separa duas floras distintas, uma composta por espécies próximas a costa atlântica úmida e outra com espécies relacionadas a Caatinga seca da depressão sertaneja.

Diversos fatores bióticos e abióticos influenciam a riqueza, abundância e distribuição de trepadeiras, dentre esses estão pluviosidade, fertilidade dos solos, topografia da paisagem, estrutura do dossel e disponibilidade de água (Gentry 1991; Schnitzer 2005; Dewalt et al. 2000, 2015). A correlação positiva observada nesse trabalho entre a riqueza de trepadeiras herbáceas e lenhosas e a altitude pode estar relacionada a maior umidade na forma de precipitação ou neblina, assim como as baixas temperaturas encontradas em áreas elevadas (Cunha 2010).

A relação entre riqueza de trepadeiras herbáceas e precipitação não tem sido objeto frequente de investigação. Os resultados observados nesse estudo diferem do padrão registrado para plantas herbáceas em ambientes sob condições estressantes, onde a riqueza desse grupo é diretamente proporcional a precipitação pluviométrica (Machado et al. 2012; Oliveira et al. 2013). O resultado encontrado nesse estudo pode ter sido influenciado por duas áreas (LUR e PCR1) com alto índice de precipitação pluviométrica $(1.300 \mathrm{~mm}$ cada) e riqueza de espécies menor ou igual as áreas inseridas na região semiárida, onde a precipitação média é menor. Apesar da complementação das coletas para cada área, a riqueza de espécies nesses dois afloramentos pode ainda estar subamostrada.
Em síntese, foi possível confirmar que os afloramentos rochosos abrigam uma elevada e heterogênea riqueza de plantas trepadeiras, e que fatores abióticos influenciam a riqueza de espécies nesse grupo, mesmo em escala local. Como recomendações para estudos futuros, pesquisas voltadas para o conhecimento taxonômico, ecológico e biogeográfico das plantas trepadeiras no nordeste do Brasil precisam ser intensificadas, especialmente em florestas secas e afloramentos rochosos.

\section{Agradecimentos}

Os autores agradecem às instituições que financiaram essa pesquisa; à CAPES (Coordenação de Aperfeiçoamento de Pessoal de Nível Superior), a concessão da bolsa de Mestrado à primeira autora; e à FACEPE (Fundação de Amparo à Ciência e Tecnologia do Estado de Pernambuco), o auxílio à mobilidade discente (AMD) concedido à primeira autora, para estágio e análise dos dados junto à equipe do Laboratório de Fitogeografia da Universidade Federal do Ceará - UFC. Agradecem também aos curadores e técnicos dos herbários visitados: CSTR, EAN, HST, PEUFR e UFP, em especial à curadora do herbário CSTR, professora $D^{a}$ Maria de Fátima de Araújo, o apoio na logística das coletas botânicas realizadas nos afloramentos rochosos do município de Patos-PB. Agradecem ainda, aos revisores anônimos, as valiosas contribuições para este trabalho.

\section{Referências}

Ab'saber A (2003) Os domínios de natureza no Brasil: potencialidades paisagísticas. Ateliê Editorial, São Paulo. 159p.

Acevedo-Rodrigues P (2003) Bejucos y plantas trepadoras de Puerto Rico e Islas Virgenes. Smithsonian Institution, Washington. 497p.

Appolinário V (2008) Taxocenose de trepadeiras em fragmentos e corredores florestais de Lavras (MG): aspectos estruturais e ecológicos. Tese de Doutorado. Universidade Federal de Lavras, Lavras. 75 p.

Araújo FS, Oliveira RF \& Lima-Verde LW (2008) Composição, espectro biológico e síndromes de dispersão da vegetação de um inselbergue no domínio da caatinga, Ceará. Rodriguésia 59: 659671.

Araújo D \& Alves M (2010) Climbing plants of fragmented area of lowland Atlantic Forest, Igarassu, Pernambuco (northeastern Brazil). Phytotaxa 8: 1-24. 
Araújo D (2014) Trepadeiras do bioma Caatinga. In: Villagra BLP, Melo MMRF, Romaniuc Neto S \& Barbosa LM (eds.) Diversidade e conservação de trepadeiras contribuição para restauração de ecossistemas brasileiros. Instituto de Botânica, São Paulo. Pp. 33-58.

Barros AAM, Ribas LA \& Araujo DSD (2009) Trepadeiras do Parque Estadual da Serra da Tiririca, Rio de Janeiro, Brasil. Rodriguésia 60: 681-694.

BFG - The Brazil Flora Group (2018) Brazilian Flora 2020: innovation and collaboration to meet Target 1 of the Global Strategy for Plant Conservation (GSPC). Rodriguésia 69: 1513-1527.

Brandão GS (2014) Composição florística de trepadeiras do parque nacional de Boa Nova, Bahia, Brasil. Dissertação de Mestrado. Universidade Estadual do Sudoeste da Bahia, Jequié. 115p.

Bongers F, Schnitzer SA \& Traore D (2002) The importance of lianas and consequences for forest management in West Africa. Bioterra 17: 59-70.

Carvalho ECD, Martins FR, Oliveira RS, Soares AA \& Araújo FS (2016) Why is liana abundance low in semiarid climates? Austral Ecology 41: 1-13.

Cerqueira RM, Gil ASB \& Meireles LD (2008) Florística das espécies arbóreas de quatro fragmentos de Floresta Estacional Semidecídua Montana na Fazenda Dona Carolina (Itatiba/Bragança Paulista, São Paulo, Brasil). Revista do Instituto Florestal 20: 33-49.

Conceição AA, Giulietti AM \& Meirelles ST (2007) Ilhas de vegetação em afloramentos de quartzito-arenito no morro do pai Inácio, Chapada Diamantina, Bahia, Brasil. Acta Botanica Brasilica 21: 335-347.

Cunha MCL (2010) Comunidades de árvores e o ambiente na Floresta Estacional Semidecidual Montana do Pico do Jabre, PB. Tese de Doutorado. Universidade Federal de Brasília, Brasília. 303p.

Delgado Júnior GC \& Alves M (2017) Diversidade de plantas trepadeiras do Parque Nacionaldo Catimbau, Pernambuco, Brasil. Rodriguésia 68: 347-377.

Dewalt SJ, Schnitzer SA \& Denslow JS (2000) Density and diversity of lianas along a chronosequence in a central panamanian lowland forest. Journal of Tropical Ecology 16: 1-19.

Dewalt SJ, Schnitzer SA, Alves LF, Bongers F, Burnham RJ, Cai Z, Carson WP, Chave J, Chuyong GB, Costa FRC, Ewango CEN, Gallagher RV, Gerwing JJ, Amezcua EG, Hart T, Ibarra-Manríquez G, Ickes K, Kenfack D, Letcher SG, Macía MJ, Makana JR, Malizia A, Martínez-Ramos M, Mascaro J, Muthumperumal C, Muthuramkumar S, Nogueira A, Parren MPE, Parthasarathy N, Pérez-salicrup DR, Putz FE, Romero-Saltos HG, Reddy MS, Sainge MN, Thomas D \& Melis JV (2015) Biogeographical patterns of liana abundance and diversity. In: Schnitzer SA, Bongers F, Burnham RJ \& Putz FE (eds.) The ecology of lianas, WileyBlackwell, Oxford. Pp. 131-146.
Domingues CAJ, Gomes VGN \& Quirino ZGM (2013) Síndromes de dispersão na maior área de proteção da Mata Atlântica paraibana. Biotemas 26: 99-108.

Durigon J \& Waechter JL (2011) Floristic composition and relations of a subtropical assemblage of climbing plants. Biodivers Conserv 20: 1027-1044.

Durigon J, Miotto STS \& Gianoli E (2014) Distribution and traits of climbing plants in subtropical and temperate South America. Journal of Vegetation Science 24: 1484-1492.

Fick SE \& Hijmans RJ (2017) WorldClim 2: new 1-km spatial resolution climate surfaces for global land areas. International Journal Climatology 37 : 4302-4315.

Fonty E, Sarthou C, Larpin D \& Ponge JF (2009) A 10 -year decrease in plant species richness on a neotropical inselberg: detrimental effects of global warming? Global Change Biology 15: 2360-2374.

Fordjour PA, Anning AK, Atakora EA \& Agyei PS (2008) Diversity and distribution of climbing plants in a semi-deciduous Rain Forest, KNUST Botanic Garden, Ghana. International Journal of Botany 4: 172-175.

França F, Melo E, Santos AKA, Melo JGAN, Marques M, Silva Filho MFB, Moraes L \& Machado C (2005) Estudos ecológico e florístico em ilhas de vegetação de um Inselberg no semi-árido da Bahia, Brasil. Hoehnea 32: 93-101.

França F, Melo E \& Gonçalves JM (2006) Aspectos da diversidade da vegetação no topo de um inselbergue no semi-árido da Bahia, Brasil. Sitientibus 6: 30-35.

Gentry AH \& Dodson C (1987) Contribuition of nontrees to species richness of a tropical rain forest. Biotropica 19: 149-156.

Gentry AG (1991) The distribution and evolution of climbing plants. In: Putz FE \& Mooney HA (eds.) The biology of vines. University Press, Cambridge. Pp. 3-39.

Gianoli E (2004) Evolution of a climbing habit promotes diversification in flowering plants. The Royal Society 271: 2011-2015.

Gianoli E, Saldaña A, Jiménez-Castillo M \& Valladares F (2010) Distribution and abundance of vines along the light gradient in a southern temperate rain forest. Journal of Vegetation Science 21: 66-73.

Gomes P \& Alves M (2009) Floristic and vegetational aspects of an inselberg in the semi-arid region of Northeast Brazil. Edinburgh Journal of Botany 66: 1-18.

Gomes P \& Alves M (2010) Floristic diversity of two crystalline rocky outcrops in the Brazilian northeast semi-arid region. Revista Brasileira de Botânica 33: 661-676.

Gomes P, Costa KCC, Rodal MJN \& Alves M (2011) Checklist of Angiosperms from the Pedra Furada Municipal Park, northeastern Brazil. Check List 7: 173-181. 
Gomes P \& Leite MS (2013) Crystalline rock outcrops in the Atlantic Forest of northeastern Brazil: vascular flora, biological spectrum, and invasive species. Brazilian Journal of Botany 36: 111-123.

Google Earth (2019) Disponível em < https://earth. google.com/web>. Acesso em 06 maio de 2019.

Gröger A (2000) Flora and vegetation of inselbergs of Vegetation Guayana. In: Porembski S \& Barthlott W (eds.) Inselbergs. Springer, Berlin. Pp. 291-314.

Hammer O, Harper DAT \& Ryan PD (2001) PAST: paleontological statistics software package for education and data analysis. Palaeontologia Electronica 4: 1-9.

Hijmans RJ, Guarino L, Cruz M \& Rojas E (2001) Computer tools for spatial analysis of plant genetic resources data: 1 DIVA-GIS. Plant Genetic Resources Newsletter 127: 15-19.

INMET - Instituto Nacional de Metereologia (2017) Disponível em $<$ http://www.inmet.gov.br/portal/>. Acesso em 01 julho de 2018.

Lucena DS, Lucena MFA, Sousa JM, Silva RFL \& Souza PF (2015) Flora vascular de um inselbergue na mesorregião do sertão paraibano, nordeste do Brasil. Scientia Plena 11: 1-11.

Lucena DS, Lucena MFA \& Alves M (2017) Climbers from two rock outcrops in the semi-arid region of Brasil. Check List 13: 417-427.

Macedo KM (2012) Florística e espectro Biológico de Afloramentos rochosos graníticos em um trecho do semiárido brasileiro. Dissertação de Mestrado. Universidade Federal de Pernambuco, Recife. 59p.

Machado Filho HO (2011) Estudo florístico de um ambiente rochoso da área de proteção ambiental (APA) do Cariri, Paraíba: riqueza, similaridade e fitogeografia. Dissertação de Mestrado. Universidade Estadual da Paraíba, Campina Grande. 106p.

Machado WJ, Prata APN \& Mello AA (2012) Floristic composition in areas of Caatinga and Brejo de Altitude in Sergipe state, Brazil. Check List 8: 1089-1101.

Matos DCL, Ferreira LV \& Salomão RP (2013) Influência da distância geográfica na riqueza e composição de espécies arbóreas em uma floresta ombrófila densa na Amazônia Oriental. Rodriguésia 64: 357-367.

Melo A, Amorim BS, Pessoa E, Maciel JR \& Alves M (2016) Serra do Urubu, a biodiversity hot-spot for angiosperms in the northern Atlantic Forest. (Pernambuco, Brazil). Check List 12: 1-25.

Morellato LPC \& Leitão Filho HF (1996) Reprodutive phenology of climbers in a Southeasthern Brasilian Forest. Biotopica 28: 180-191.

Mori SA, Silva LAM, Lisboa G \& Coradin L (1985) Manual de manejo do herbário fanerogâmico. Centro de Pesquisas do Cacau, Ilhéus. 97p.

Oliveira Filho AT \& Machado JNM (1993) Composição florística de uma floresta semidecídua montana na serra de São José, Tiradentes, Minas Gerais. Acta Botânica Brasílica 7: 71-88.
Oliveira ACP, Mota ML \& Loiola MIB (2012) Diversidade florística e chave de identificação de trepadeiras em uma floresta estacional semidecidual em Parnamirim - RN, Brasil. Caatinga 25: 153-158.

Oliveira DG, Prata AP \& Ferreira RA (2013) Herbáceas da Caatinga: composição florística, fitossociologia e estratégias de sobrevivência em uma comunidade vegetal. Revista Brasileira de Ciências Agrárias 8: 623-633.

Oliveira DG, Matos GMA \& Prata APN (2015) Diversidade florística e estratégias de sobrevivência em um fragmento de Caatinga em porto da folha Sergipe, Brasil. Biotemas 28: 51-60.

Pijl VL (1982) Principles of dispersal in higher plants. Springer Verlag, New York. 162p.

Porembski S, Martinelli G, Ohlemuller R \& Barthlott W (1998) Diversity and ecology of saxicolous vegetation mats on inselbergs in the Brazilian Atlantic Rainforest. Diversity and Distributions 4: 107-119.

Porembski S (2000) The invasibility of tropical granite outcrops ('inselbergs') by exotic weeds. Journal of the Royal society of Western Australia 83: 131-137.

Porembski S (2007) Tropical inselbergs: habitat types, adaptive strategies and diversity patterns. Revista Brasileira de Botânica 30: 579-586.

Porto PAF, Almeida A, Pessoa W, Trovão JD \& Felix LP (2008) Composição florística de um inselbergue no agreste paraibano, município de Esperança, nordeste do Brasil. Revista Caatinga 21: 214-223.

R Core Team (2018) R: a language and environment for statistical computing. R Foundation for Statistical Computing, Vienna. Disponível em $<$ https:// www.R-project.org/>. Acesso em 6 maio 2019.

Rodal MJN, Sales MF, Silva MJS \& Silva AGS (2005) Flora de um brejo de altitude na escarpa oriental do Planalto da Borborema, PE, Brasil. Acta Botânica Brasílica 19: 843-858.

Rodal MJN \& Sales MF (2007) Composição da flora vascular em um remanescente de floresta montana no semi-árido do nordeste do Brasil. Hoehnea 34: 433-446.

Rodal MJN, Barbosa MRV \& Thomas WW (2008) Do the seasonal forests in Northeastern Brazil represent a single floristic unit?. Brazilian Journal of Biology 68: 631-637.

Rundel PW \& Franklin T (1991) Vines in arid and semi-arid ecosystems. In: Putz FE \& Mooney HA (eds.) The Biology of the vines. University Press, Cambridge. Pp. 337-356.

Sales-Rodrigues J \& Brasileiro JCB (2014) Flora of a inselberg in the mesorregion of the Paraiba state, Brazil. Polibotânica 37: 47-61.

Sampaio EVSB (2003) Caracterização da caatinga e fatores ambientais que afetam a ecologia das plantas lenhosas. In: Sales VC (ed.) Ecossistemas brasileiros: manejo e conservação. Expressão Gráfica e Editora, Fortaleza. Pp. 129-142. 
Scarano FR (2007) Rock outcrop vegetation in Brazil a brief overview. Revista Brasileira de Botânica 30: 561-568.

Schnitzer SA (2005) A mechanistic explanation for global patterns of liana abundance and distribution. The American Naturalist 166: 262-276.

Scudeller VV, Martins FR \& Shepherd GJ (2001) Distribution and abundance of arboreal species in the Atlantic Ombrophilous Dense Forest in Southeastern Brazil. Plant Ecology 152: 185-199.

Silva MCNA \& Rodal MJN (2009) Padrões das síndromes de dispersão de plantas em áreas com diferentes graus de pluviosidade, PE, Brasil. Acta botânica Brasílica 23: 1040-1047.

Sperry JS, Meinzer FC \& McCulloh KA (2008) Safety and efficiency conflicts in hydraulic architecture: scaling from tissues to trees. Plant, Cell and Environment 31: 632-645.

Tölke EEAD, Silva JB, Pereira ARL \& Melo JIM (2011) Flora vascular de um inselbergue no estado da Paraíba, nordeste do Brasil. Revista Biotemas 24: 39-48.

Udulutsch RG, Assis MA \& Picchi DG (2004) Florística de trepadeiras numa floresta estacional semidecídua, Rio Claro-Araras, estado de São Paulo, Brasil. Revista Brasileira de Botânica 27: 125-134.

Udulutsch RG, Souza VC, Rodrigues RR \& Dias P (2010) Composição florística e chaves de identificação para as lianas da Estação Ecológica dos Caetetus, estado de São Paulo, Brasil. Rodriguésia 61: 715-730.
Vargas BC, Araújo GM, Schiavini I, Rosa PO \& Hattori EKO (2013) Florística de trepadeiras em floresta semidecidual e em mata ciliar no vale do Rio Araguari, MG. Bioscience Journal 29: 185-197.

Vargas BC \& Araújo GM (2014) Florística de trepadeiras em fragmentos de florestas semideciduais em Uberlandia, Minas Gerais, Brasil. Rodriguésia 65: 49-59.

Vargas BC, Oliveira APC, Udulutsch RG, Marcusso GM, Sabino GP, Melo PHA, Grillo RMM, Kamimura VA \& Assis MA (2018) Climbing plants of Porto Ferreira State Park, Southeastern Brasil. Biota Neotropica 18: 1-9.

Veloso HP, Rangel Filho ALR \& Lima JCA (1991) Classificação da vegetação brasileira adaptada a um sistema universal. IBGE, Departamento de Recursos Naturais e Estudos Ambientais, Rio de Janeiro. 124p.

Villagra BLP (2012) Estrutura da comunidade de trepadeiras em Mata Atlântica, Santo André, SP, Brasil. Dissertação de Mestrado. Universidade de São Paulo, São Paulo. 150p.

Villagra BLP \& Romaniuc Neto S (2014) Nomenclatura das plantas de hábito trepador. In: Villagra BLP, Melo MMRF, Romaniuc Neto S \& Barbosa LM (eds.) Diversidade e conservação de trepadeiras, contribuição para restauração de ecossistemas brasileiros. Instituto de Botânica, São Paulo. Pp. 01-12.

Zar JH (1996) Biostatistical Analysis. $3^{\text {rd }}$ ed. Prentice Hall, New Jersey. 662p. 